\title{
PENGGUNAAN BAHASA JERMAN DALAM BIDANG PARIWISATA (DEUTSCH FÜR TOURISMUS)
}

\author{
Surya Masniari Hutagalung \\ Universitas Negeri Medan
}

\begin{abstract}
Abstrak: Artikel ini memaparkan penggunaan bahasa Jerman dalam Bidang Pariwisata. Maksud paparan ini adalah sebagai tindak lanjut dari sebagian kecil hasil tracer study yang dilakukan untuk pengembangan perangkat pembelajaran mata kuliah Deutsch für Tourismus, di bawah penelitian "Kontribusi Tracer Study terhadap Pengembangan Perangkat Pembelajaran Deutsch für Tourismus". Berdasarkan hasil wawancara dengan beberapa pemandu wisata berbahasa Jerman ada beberapa kosa kata yang belum pernah disebut dalam bahasa Jerman di bidang pariwisata. Pemandu wisata melakukan peminjaman kata dari Bahasa Inggris. Oleh sebab itu dilakukan pemetaan kosa kata tersebut dan dideskripsikan. Artikel ini memaparkan hasil pemetaan dan deskripsi kosa kata tersebut.
\end{abstract}

Kata kunci: Bahasa Jerman, Pariwisata, Deutsch für Tourismus

Abstract: This article describes the use of German in Tourism. The purpose of this presentation is as a follow up to a small part of the results of the tracer study conducted for the development of the Deutsch für Tourismus course, under the research "Contribution of the Tracer Study to the Development of the Deutsch für Tourismus Learning Device". Based on interviews with several German-speaking tour guides, there are some vocabularies that have never been mentioned in German in the field of tourism. The tour guide borrows words from English. Therefore the mapping of the vocabulary is done and described. This article presents the results of the mapping and description of the vocabulary.

Keyword: German, Tourism, Deutsch für Tourismus

\section{PENDAHULUAN}

Bahasa Jerman dalam komunikasi sehari-hari membutuhkan empat penguasaan keterampilan berbahasa, yakni keterampilan membaca, menulis, mendengar dan berbicara. Keterampilan berbahasa dapat dikuasai jika memiliki penguasaan kosa kata dan gramatik yang baik. Kosa kata Bahasa Jerman dalam bidang pariwisata sangat penting dikuasai oleh mahasiswa Bahasa Jerman Universitas Negeri Medan. Hal tersebut menjadi kewajiban, mengingat salah satu Profil Lulusan Prodi Pendidikan Bahasa Jerman Unimed adalah sebagai Professional Muda yang bergerak pada Managemen Dunia Pariwisata. Artinya dengan Profil tersebut diisyaratkan, bahwa lulusan Prodi Pendidikan Bahasa Jerman mampu menjadi pemandu wisata, 
mampu menjadi manager biro perjalanan, bahkan mampu menjadi pemilik kantor perjalanan wisata. Oleh sebab itu perlu pembenahan perkuliahan dalam bidang pariwisata, agar mahasiswa tidak ragu untuk menekuni bidang pariwisata, karena kurikulum sudah disiapkan untuk memfasilitasi Profil yang telah disusun.

Guna membekali mahasiswa dalam penguasaan materi dalam bidang pariwisata, dimunculkan mata kuliah Deutsch für Tourismus. Perangkat pembelajaran untuk mata kuliah tersebut belum lengkap, sehingga perlu disusun dengan baik, agar bisa menjadikan mahasiswa siap terjun pada dunia nyata di bidang pariwisata.

Penulis melakukan penelitian pengembangan Perangkat Pembelajaran Mata Kuliah Deutsch für Tourismus berdasarkan Tracer Study Pengguna Lulusan dan Alumni. Tracer Study dilakukan sebagai bahan analisis kebutuhan. Sehingga diharapkan, informasi yang diperoleh dari pengguna lulusan adalah informasi yang berguna untuk menambah pengetahuan dan keterampilan mahasiswa dalam bidang pariwisata. Hasil tracer studi berkontribusi terhadap pengembangan perangkat pembelajaran.

Artikel ini memaparkan sebagian kecil dari hasil penelitian, yakni kosa kata Bahasa Jerman terkait bidang Pariwisata. Sesuai dengan hasil tracer study yang menyebutkan, bahwa ada beberapa kosa kata dalam bidang pariwisata yang selalu disebut dalam Bahasa Inggris, karena tidak diketahui kosa kata tersebut dalam bahasa Jerman. Data ini disampaikan oleh beberapa pemandu wisata berbahasa Jerman.

Kosa kata dalam Bidang Pariwisata sangat penting dikuasai, agar mahasiswa mampu bercerita dalam bahasa Jerman terkait bidang pariwisata, walau hanya sederhana. Freudenstein (dalam Storch, 2009:55) menyatakan, bahwa penguasaan kosa kata jauh lebih penting daripada penguasaan grammatik dalam berkomunikasi, terutama dalam komunikasi bahasa asing. Drowdoski (1983:20) menyatakan bahwa kosa kata adalah kesatuan kata-kata yang digunakan secara aktif oleh pembicara atau penulis. Artinya jika penutur bahasa asing tidak menguasai kosa kata, maka penutur tersebut tidak akan mampu berkomunikasi dalam bahasa asing tersebut dengan baik. Demikian pentingnya kosa kata, sehingga pada penelitian yang dilakukan kosa kata Bahasa Jerman bidang pariwisata dibahas secara tuntas, terutama dalam pengembangan buku ajar Deutsch für Tourismus.

\section{KAJIAN PUSTAKA}

Kosa kata Bahasa Jerman dalam bidang pariwisata mencakup kosa kata terkait bidang perhotelan, perjalanan, objek-objek wisata, dan budaya di Sumatera Utara. Kosa kata yang diberikan setara dengan kosa kata Bahasa Jerman Level B1 Standar Eropa. Adapun kemampuan kosa kata terkait level B1 (Goethe Institut, 2018) adalah:

- dapat memahami topik utama dari pokok bahasan tertentu yang lazim dibicarakan seperti: pekerjaan, pendidikan, waktu senggang dll, apabila dalam percakapan tersebut digunakan bahasa Jerman standar yang mudah dimengerti.

- dapat mengatasi hampir semua situasi berkenaan dengan kemampuan berbahasa ketika 
berada di negara-negara berbahasa Jerman.

- dapat menjabarkan dengan mudah dan kontekstual pokok-pokok bahasan tertentu yang lazim dibicarakan dan pokok-pokok bahasan yang Anda sukai yang berkaitan dengan diri Anda sendiri.

- dapat menceritakan pengalamanpengalaman dan kejadiankejadian, dapat menjabarkan impian, harapan dan tujuan hidup, juga dapat memberikan alasan atau penjelasan singkat.

\section{Metode Penelitian}

Penelitian yang dilakukan adalah penelitian pengembangan, yang mengadopsi model pengembangan Plomp. Plomp (1997: 6-15) menyusun model pengembangan ke dalam empat langkah, yaitu (1) fase investigasi, (2) fase design, (3) fase realisasi atau konstruksi, (4) fase tes, evaluasi, dan revisi. Fase investigasi adalah fase merencanakan, mengidentifikasi kebutuhan dan hal-hal terkait. Pada fase tersebut dilaksanakan tracer study. Salah satu hasil tracer study adalah pentingnya penyusunan kosa kata Bahasa Jerman bidang Pariwisata. Kegiatan tersebut dapat dilihat pada skema berikut.

\section{Investigasi:}

- Identifikasi kebutuhan tracer study

\section{Design:}

- Rancangan perangkat, buku ajar, media

\section{Realisasi \& Konsultasi:}

- Pengembangan perangkat, buku ajar, media sesuai design

\section{Tes, Evaluasi, Revisi:}

- Validasi ahli, uji coba
Pelaksanaan tracer study memiliki langkah kegiatan tersendiri, di samping langkah pengembangan buku ajar. Adapun tahap-tahap pelaksanaan tracer study adalah sebagai berikut.

\section{Perencanaan:}

- Penyusunan rencana kerja.

- Penyusunan instrumen/ angket.

- Mencari data responden.

2. Persiapan:

- Validasi instrumen.

- Penentuan tim penyebar angket.

- Pengajuan responden.

- Sistem pelaksanaan

\section{Tahap Pelaksanaan:}

- Coaching Tim Penyebar Angket.

- Pembagian Kerja

- Penyebaran Angket/ Pertemuan dengan responden.

- Pelaksanaan wawancara.

- Pemantauan hasil pengisian angket.

- Pengumpulan angket.

- Kunjungan ke responden.

- Pengumpulan akhir angket

\section{Tahap Akhir:}

- Pertemuan Tim

- Pengumpulan semua angket

- Reduksi Data

- Analisis Data

Penyusunan penggunaan kosa kata bersumber dari laporan tracer study yang menyebut bahwa banyak kosa kata bidang pariwisata yang terpaksa disebut dalam bahasa internasional, yaitu bahasa Inggris, karena kekurang tahuan penyebutan istilah pariwisata dalam Bahasa Jerman. 


\section{PEMBAHASAN}

Bagian ini akan memaparkan beberapa kosa kata Bahasa Jerman bidang Pariwisata, yang sering disebut dalam Bahasa Inggris, yang penyebutannya dalam Bahasa Jerman tidak diketahui pemandu wisata. Kosa kata ini hanya sebagian kecil dari banyak kosa kata Bahasa Jerman bidang pariwisata, terdiri dari budaya, perhotelan, transportasi, dan objek wisata. Paparan kosa kata yang jarang dijumpai dalam Bahasa Jerman di lapangan adalah sebagai berikut.

Tabel 1. Kosakata Bahasa Jerman Pariwisata

\begin{tabular}{|c|c|}
\hline $\begin{array}{c}\text { Bahasa Indonesia atau } \\
\text { deskripsi }\end{array}$ & Bahasa Jerman atau Deskripsi \\
\hline $\begin{array}{l}\text { Pemandu Wisata sering } \\
\text { disebut dengan kata Guide, } \\
\text { dan di Indonesia hanya ada } \\
\text { satu jenis guide yang bisa } \\
\text { memandu ke semua } \\
\text { bidang wisata }\end{array}$ & $\begin{array}{l}\text { Der Reiseleiter. Pemandu wisata dalam bahasa Jerman } \\
\text { dapat dibagi lagi ke dalam beberapa kategori, } \\
\text { tergantung spesialianya, antara lain (1) Wanderführer, } \\
\text { (2) Kunstreiseführer, (3) Szenereiseführer, } \\
\text { Reisemarktführer, dst. }\end{array}$ \\
\hline $\begin{array}{l}\text { Peta sering disebut dengan } \\
\text { Map atau Townmap }\end{array}$ & Die Wegbeschreibung oder Stadtplan \\
\hline $\begin{array}{l}\text { Pemesanan sering disebut } \\
\text { Booking }\end{array}$ & Die Reservierungbestätigung \\
\hline $\begin{array}{l}\text { Keliling kota sering disebut } \\
\text { Stadtround, gabungan } \\
\text { bahasa Jerman dan Inggris }\end{array}$ & bummeln \\
\hline $\begin{array}{l}\text { Panjat gunung sering } \\
\text { disebut hiking }\end{array}$ & Steinschleppen \\
\hline Ulos dalam bahasaBatak & $\begin{array}{l}\text { Kata ini tak dijumpai dalam Bahasa Jerman sehingga } \\
\text { perlu dideskripsikan sebagai wie ein Schal aber } \\
\text { funktioniert nicht gleich. Es ist traditionelle Schal, nur } \\
\text { in Kulturveranstalltung zu tragen. }\end{array}$ \\
\hline
\end{tabular}

\section{PENUTUP}

Kosakata Bahasa Jerman bidang pariwisata senantiasa berkembang mengikuti zaman, sehingga kosa kata yang diadopsi dari bahasa Inggris yang biasanya digunakan, sebaiknya disebut dalam Bahasa Jerman asli. Paparan di atas merupakan kosa kata bahasa Jerman bidang pariwisata yang diambil dari berbagai sumber di atas tahun 2015 .

\section{DAFTAR PUSTAKA}

Drowdoski, Günther. 1983. Der Große Duden Grammatik. Mannheim, Wien, Zürich: Dudenverlag:

Goethe Institut. 2018. Storch, Günther. 2009. Deutsch als Fremdspracheeine Didaktik, Paderborn-Germany: Wilhelm Fink GmbH \& Co Verlags-KG 